\title{
Formation of multiple combustion fronts in an imbert downdraft gasification reactor
}

\author{
Kittipass Wasinarom ${ }^{1}$, Sarawut Sungworagarn ${ }^{2}$, Prasan Sathitruangsak ${ }^{2}$ and Kasemsil Onthong, S $^{3}$ \\ ${ }^{1}$ School of International and Interdisciplinary Engineering Programs, School of Engineering, King Mongkut's Institute \\ of Technology Ladkrabang, 1 Soi Chalong Krung 1, Chalong Krung Road, Ladkrabang Bangkok, 10520, Thailand \\ ${ }^{2}$ Department of Mechanical Engineering, Faculty of Engineering and Technology, Mahanakorn University of Technology \\ 140 Cheum-Sampan Road, Nong-Chok, Bangkok 10530, Thailand \\ ${ }^{3}$ Department of Teacher Training in Mechanical Engineering,King Mongkut's University of Technology North Bangkok, \\ 1518 Phacharat 1 Road., Bang Sue, Bangkok 10800, Thailand
}

\begin{abstract}
The experimental study of downdraft gasification was performed in this paper. The operation which led to the formation of the second combustion front was pointed out. In this situation, both combustion fronts will lose their intensity and finally be extinguished. The operation was unintentionally stopped. It was revealed that the combustion front propagated upward in the reactor after starting the test. While it was about to reach the air inlet nozzle, the second combustion front was detected by an abrupt temperature rise of the thermocouple above the air supply nozzle. After the formation of the second combustion front, both fronts started to lose their intensity which indicated by the decrease in temperature corresponding with their locations. It was possible that the second combustion front would dilute the oxygen concentration supplied to the first combustion front. The decreasing temperature of the first combustion front reduced the heat transfer rate to the second combustion front. Finally, both combustion fronts were extinguished. The operation was unintentionally stopped.
\end{abstract}

Keyword. Gasification, Imbert type, Downdraft, biomass, Reactor.

\section{Introduction}

Solid fuel combustion is a highly complex process. Beginning with the pyrolysis process, the fresh fuel undergoes thermal decomposition which releases the combustible gas and condensable heavy hydrocarbon. Then, the released gas is reacted with air to produce thermal energy. The continuous combustion process can be sustained by utilizing a portion of the produced thermal energy back to supply the pyrolysis process of the remaining fresh fuel. After releasing all volatile gas, the surface heterogeneous combustion is continued on the left-over fixed carbon (char). Finally, the fixedcarbon is then consumed leaving the non-combustible ash as the residual.

Gasification is considered a more efficient means of solid fuel combustion compared with direct combustion. It has more capability to improve producer gas heating value before reacting with air. In gasification, the pyrolysis gas undergoes a shift reaction within the reduction layer. The combustible $\mathrm{CO}$ was increased by the consumption of non-combustible $\mathrm{CO}_{2}$. Heavy hydrocarbons (tar) are also converted to lighter gas molecules in the reduction layer. These resulted in the increase of synthesis gas heating value.

The combustion front propagation in fixed bed gasification was studied by many researchers [1] [2]. In downdraft gasification, the propagation was explained by diffusion transport of heat from the reaction front and the generated pyrolysis gas in counter direction with the supply air. Therefore, the reaction front moves upward at a finite speed. The speed of the moving front depends on the rate of heat transfer from the combustion front and the rate of combustible pyrolysis gases accumulation above the combustion front. When the air-fuel mixture and the temperature is falling within the flammability range. The mixture will auto-ignite with the incoming oxygen resulting in the combustion front moving upward. The front propagation will never happen in a downward direction for downdraft configuration because there is no oxygen left below the front. The propagation speed depends on many factors, for example, the fuel type and size, air mass flow rate, the fuel moisture composition [3].

The homogeneous combustion front of fixed bed gasification is identical to the $1 \mathrm{D}$ gas-phase lamina flame except that the reaction front occurs inside the pore space of the stacked fuel bed. These reaction fronts are very thin. It has a length in the order of $1 \mathrm{~mm}$. The heat transfer around the combustion front inside the fuel bed is governed by radiation and convection of hot combusted mixture to the fuel particle surface that makes up the pore space. The heat conduction among stacked fuel particles has little effect compared to other heat

* Corresponding author: kasemsilo@kmutnb.ac.th 
transfer modes due to the high contact conduction resistance between stacked particles and the high thermal resistance of the wooden biomass [4]. It was found that the temperature profile along the height of the fuel bed has a milder gradient and spreads over a longer distance around the combustion front compared to the conventional gas-fueled combustion front. The temperature profile and heat transfer mechanism are identical to the combustion in the inert porous media which was illustrated by [5].

In this paper, the experimental study of downdraft gasification has been performed. The operation which led to the formation of the second combustion front was pointed out. This allows operators to understand the insight of the events.

\section{Experimental procedure}

A cylindrical shape Imbert type gasification reactor was used in this test [6]. It is made of steel with an inner diameter of $75 \mathrm{~mm}$ and $500 \mathrm{~mm}$ height as shown in figure 1. The door was attached along with the height of the reactor which allowed the operators to investigate the fuel evolution in different layers after finishing the test as shown in figure 2. The reactor was well insulated during the test. The three inlet supply air nozzles were installed at $230 \mathrm{~mm}$ from the bottom where the fuel grate was located. Type-K thermocouples were installed to measure temperature distribution along with the reactor height. The supply air mass flow rate was measured by an air rotameter. The reading temperature was recorded by the MW-100 data logger. Testo 350 flue gas analyzer was used to measure $\mathrm{O}_{2}, \mathrm{CO}$, and $\mathrm{CO}_{2}$ gas composition.

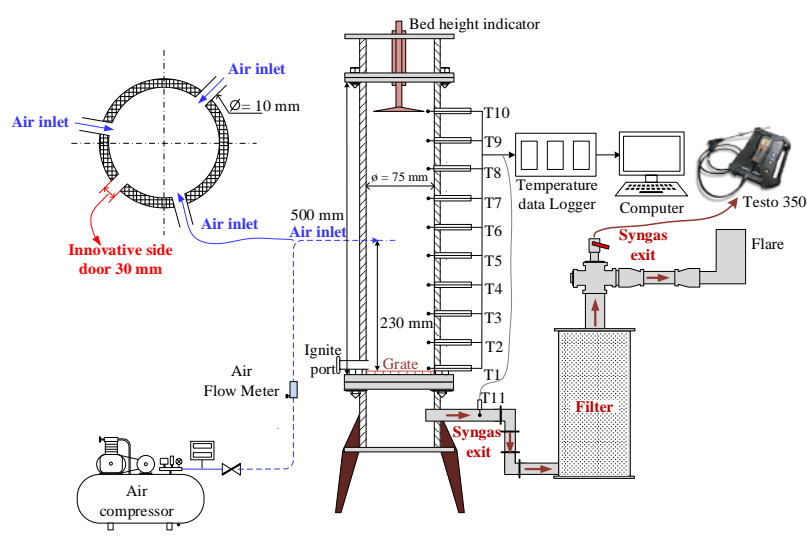

Fig. 1. Schematic diagram for downdraft gasification.

The $250 \mathrm{~g}$ of rice husk was filled in the reactor which corresponded to the $450 \mathrm{~mm}$ height of the fuel bed. The feedstock property is shown in table 1. Air was introduced to the reactor at the desired flow rate by three nozzles. The flow rate was regulated by a ball valve to satisfy each of the test conditions in table 2 . Then, the portable butane burner was put in the ignite port. The reading $T_{1}$ was monitored until the reading $T_{1}$ raised to 100 C. After that, the ignition port was closed. The temperature and gas composition were started recorded for every 2 minutes interval until the test was finished. Finally, the recorded data were interpreted as a series of events.

Table 1. Proximate and Ultimate Analyses of Rice Husk.

\begin{tabular}{|c|c|c|c|c|}
\hline \multicolumn{5}{|c|}{$\begin{array}{c}\text { Ultimate Analysis } \\
(\%, \text { as received) }\end{array}$} \\
\hline $\mathrm{C}$ & $\mathrm{H}$ & $\mathrm{O}$ & $\mathrm{N}$ & $\mathrm{S}$ \\
\hline 38.0 & 4.55 & 32.4 & 0.69 & 0.60 \\
\hline \multicolumn{5}{|c|}{$\begin{array}{c}\text { Proximate Analysis } \\
(\%, \text { as received) }\end{array}$} \\
\hline Volatile & $\begin{array}{c}\text { Fixed } \\
\text { carbon }\end{array}$ & Moisture & Ash & $\begin{array}{c}\mathrm{HHV} \\
(\mathrm{MJ} / \mathrm{kg})\end{array}$ \\
\hline 55.6 & 20.1 & 10.3 & 14.0 & 15.0 \\
\hline
\end{tabular}

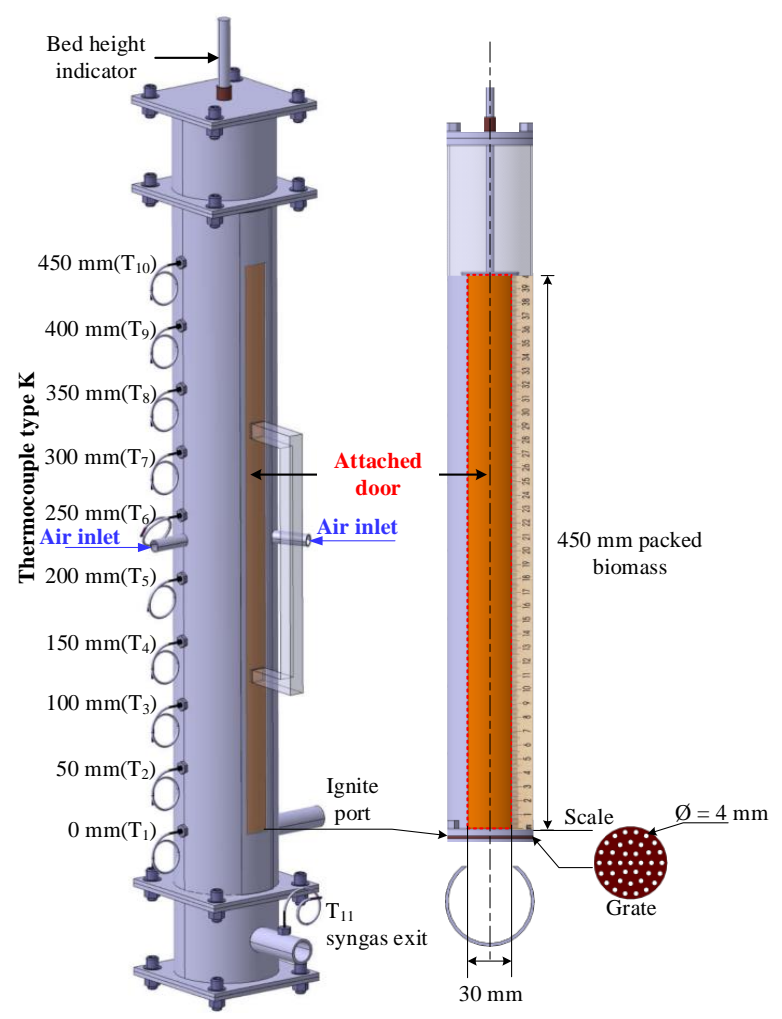

Fig. 2. Configuration of the packed bed reactor used for downdraft gasification.

Table 2. Experimental condition.

\begin{tabular}{|c|c|}
\hline Air flow rate (1/min) & Air mass flux (kg/ $\left.\mathbf{m}^{\mathbf{2}}-\mathbf{h}\right)$ \\
\hline 15 & 255 \\
\hline 20 & 340 \\
\hline 30 & 680 \\
\hline
\end{tabular}

\section{Result and discussion}

For all cases, the measured temperature showed that the combustion front propagated upward to the top of the reactor as the peak temperature continually moved upward during the test. This was in agreement with other research papers on downdraft front propagation [1] [7] [8]. The increasing peak temperature along the testing period (Fig 4a, 4b, and $4 \mathrm{c}$ ) reflected the increase in 
combustion intensity. For air mass flux 340 and 680 $\mathrm{kg} / \mathrm{m}^{2}-\mathrm{h}$, the $\mathrm{CO}$ was increased with the increasing time but the $\mathrm{CO}_{2}$ was decreased along with the increasing time (Fig 3b and 3c). This could be explained by the intensification of the shift reaction that occurred just below the combustion front. The evidence of the shift reaction was pronounced in the case with the higher air mass flux because the higher combustion gas temperature boosted the shift reaction and tars cracking below the reaction front. There were researchers who mention the direct relation between peak combustion temperature at the reaction front and $\mathrm{CO}$ concentration in producer gas [8] [9].

For all cases of the input air mass flux, when the combustion front was about to reach the supply air nozzle location, the second combustion front was formed above the air supply nozzle ( $\mathrm{T}_{6}$ location). The forming of the second combustion front could be detected by the raising of the measured $T_{6}$ as shown in the figure $4 a, 4 b$, and 4c. This could be described by many possible incidents that led to the presence of oxygen, combustible gas (pyrolysis gas) and temperature that allowed the ignition to be taking place at that location. The first incident that led to the presence of oxygen above the air supply nozzle is the high dispersion of the flow inside the cavity of the porous media [10]. The flow inside porous media is identical to the flow inside the pore space of the stacked fuel bed. Air was injected into the reactor by the supply nozzle. The high dispersion flow allows the inlet air to transport over a wide area of the inlet location. Some portion of the inlet air is transported to the area above the inlet nozzle resulting in a high concentration of oxygen. The second and third incidents that led to the presence of the combustible gas (pyrolysis gas) and high temperature above the air inlet nozzle is the diffusion transport of pyrolysis gas and heat energy that produced from the first combustion front. Which at that time, propagated to the location just below the inlet air nozzle. The second reaction front is the updraft configuration since it consumes oxygen that disperses upward from the air nozzle.

After the ignition of the second combustion front, both fronts started to lose their intensity which indicated by the decreasing in temperature corresponding with their locations. It was possible that the second combustion front released non-combustible gas and consumed some portion of the supplied oxygen. Which results in the dilution of the oxygen that flowed down to supply the first combustion front. The falling temperature of the first combustion front resulted in decreased heat transfer rate to the second combustion front. Therefore, the second combustion front was extinguished without enough heat supply. Finally, both combustion fronts were extinguished. The operation was unintentionally stopped.

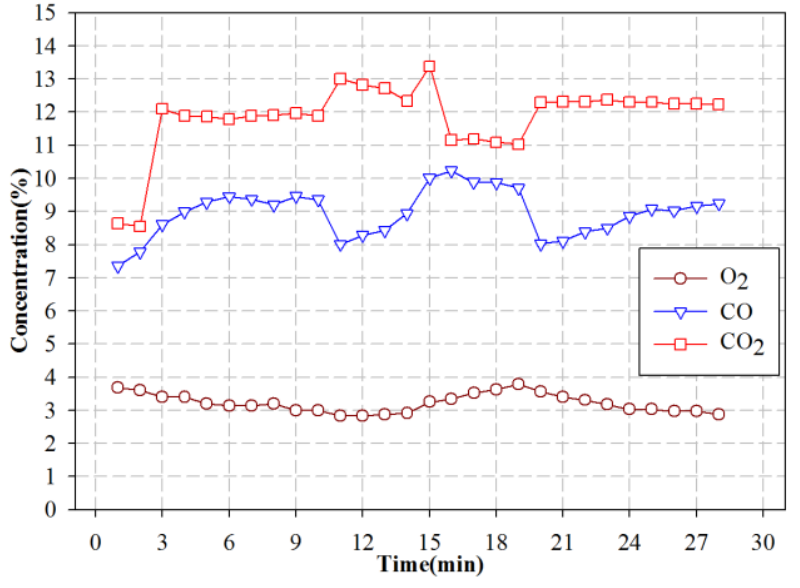

(a) $255 \mathrm{~kg} / \mathrm{m}^{2}-\mathrm{h}$

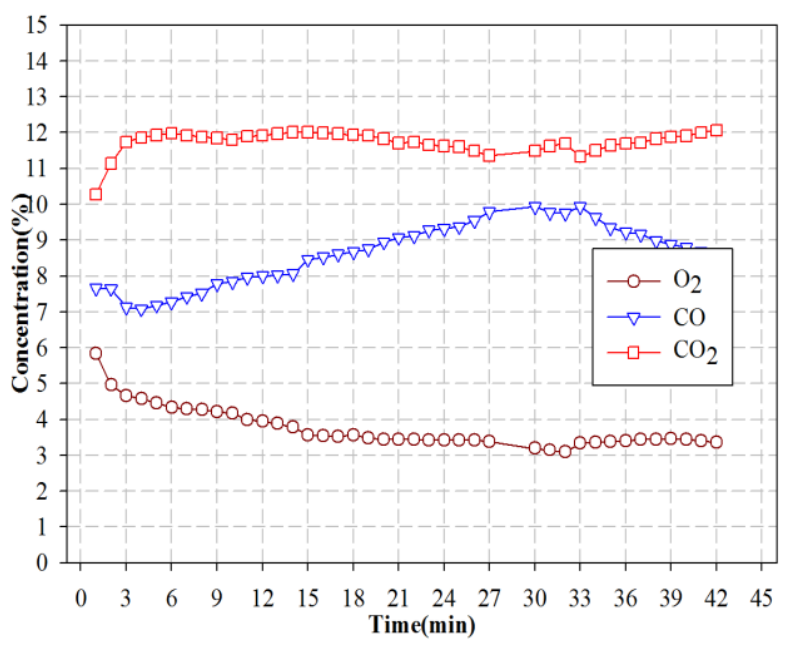

(b) $340 \mathrm{~kg} / \mathrm{m}^{2}-\mathrm{h}$

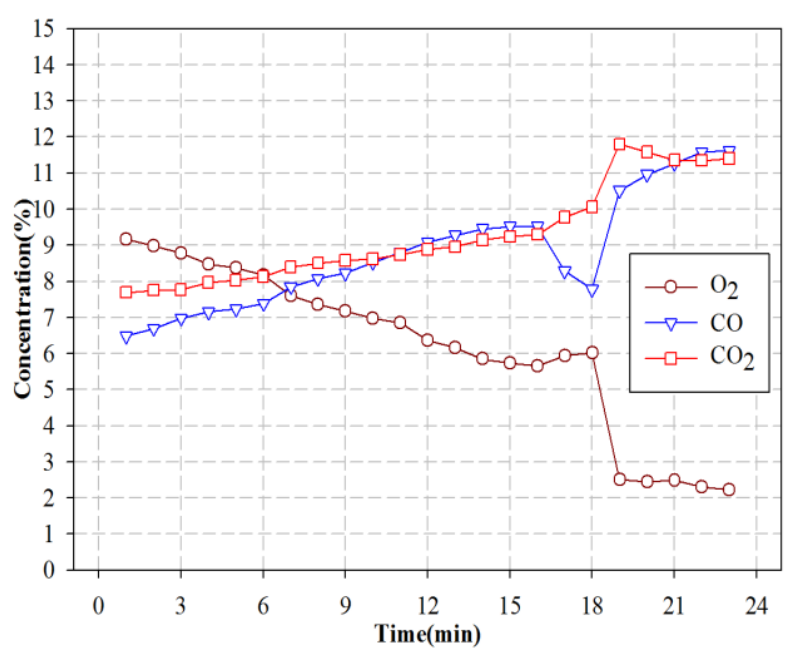

(c) $680 \mathrm{~kg} / \mathrm{m}^{2}-\mathrm{h}$

Fig. 3. Gas composition at the different time. 


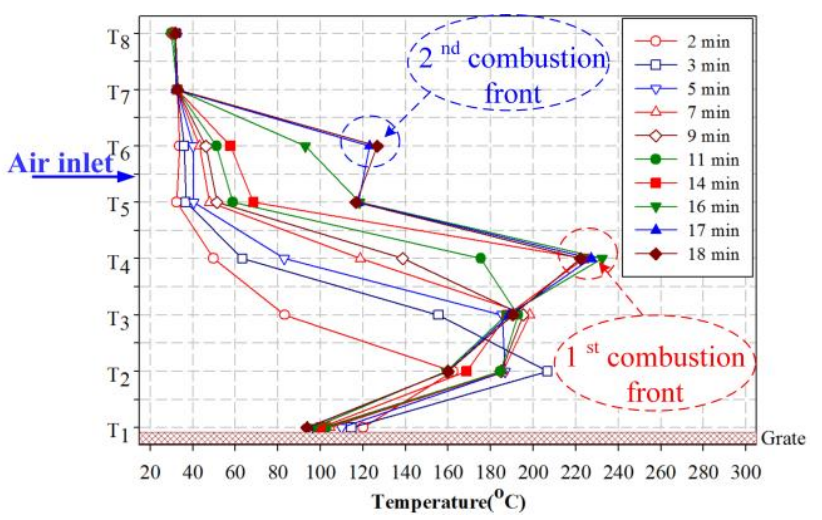

(a) $255 \mathrm{~kg} / \mathrm{m}^{2}-\mathrm{h}$

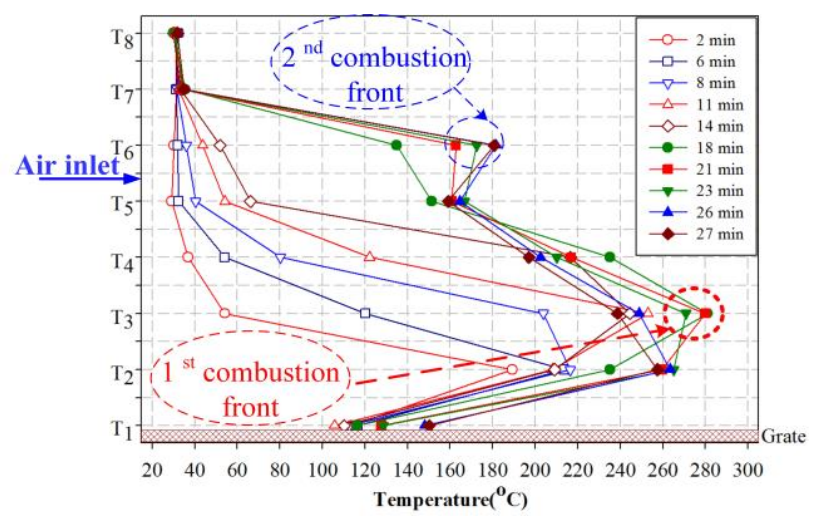

(b) $340 \mathrm{~kg} / \mathrm{m}^{2}-\mathrm{h}$

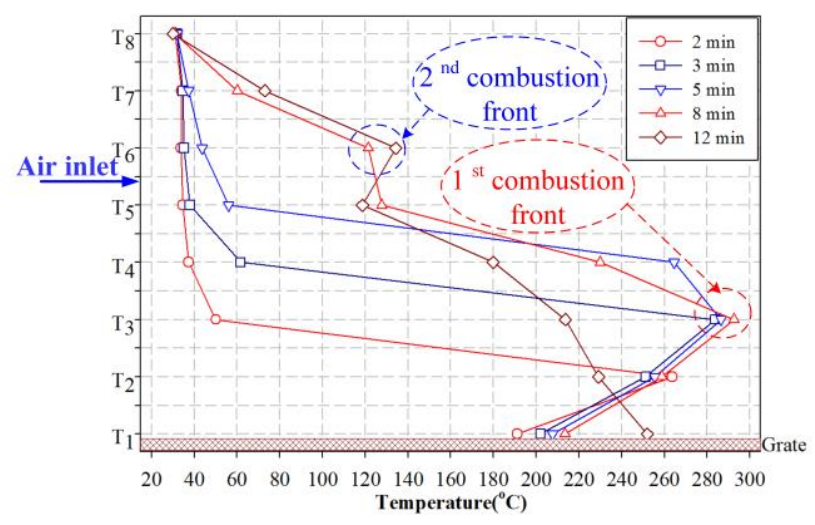

(c) $680 \mathrm{~kg} / \mathrm{m}^{2}-\mathrm{h}$

Fig. 4. Temperature profile inside the reactor at the different time.

After the flame extinguished, the reactor was left until it cooled down to a temperature below $50{ }^{\circ} \mathrm{C}$. The attached door was opened to investigate the fuel evolution in different layers as shown in tablrure 5. The black char residual above the air inlet nozzle proved that the pyrolysis combustion has occurred by consuming the dispersed air above the air nozzle.

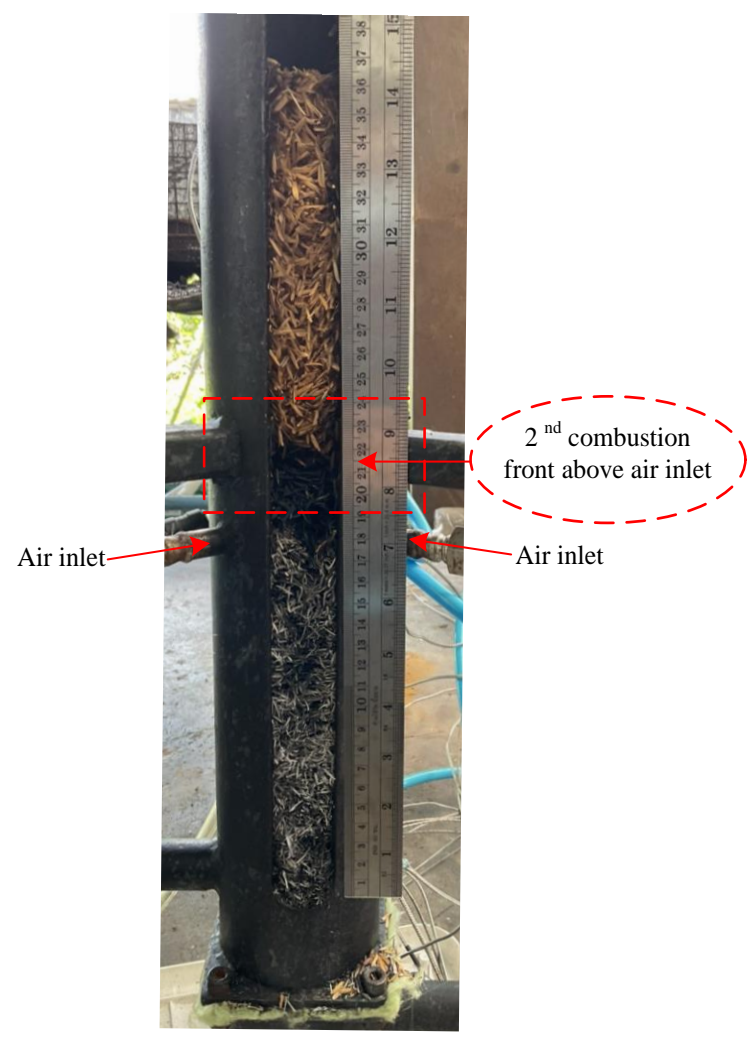

Fig. 5. Residual investigation by opening the attached door.

\section{Conclusion}

The experimental study of downdraft gasification was performed in this paper. The operation which led to the formation of the second combustion front was pointed out. In this situation, both combustion fronts will lose their intensity and finally be extinguished. Air was injected by nozzles at the throat area of the stacked fuel bed. In the beginning, the combustion front was ignited underneath the reactor. After that, the combustion front propagated upward in the reactor during the test. While it was about to reach the air inlet nozzle, the second combustion front was detected by an abrupt temperature rise of the thermocouple above the air supply nozzle. After the formation of the second combustion front, both fronts started to lose their intensity indicated by the decrease in temperature corresponding with their locations. It was possible that the second combustion front would dilute the oxygen concentration supplied to the first combustion front. The decreasing temperature of the first combustion front reduced the heat transfer rate to the second combustion front. Finally, both combustion fronts were extinguished. The operation was unintentionally stopped.

\section{Acknowledgement}

This work is supported by King Mongkut's Institute of Technology Ladkrabang [KREF186414]. 


\section{References}

1. C. Ryu, A.N. Phan, V.N. Sharifi and J. Swithenbank ,Co-combustion of textile residues with cardboard and waste wood in a packed bed, Experimental Thermal and Fluid Science, 32, (2007): 450-458.

2. K. Onthong, J. Chareonsuk, A New Method for Zone Development Observation for Updraft Rice Husk Gasification, BioResources, 14, 3(2019): 5080 $-5096$

3. S. Mahapatra and S. Dasappa, Experiments and analysis of propagation front under gasification regimes in a packed bed, Fuel Processing Technology., 121, (2014): 83-90.

4. M. Jingwen and B. Heng, Measurements and theoretical modeling of effective thermal conductivity of particle beds under compression in air and vacuum, Case Studies in Thermal Engineering., 10, (2017): 423-433.

5. K. Wasinarom, J. Charoensuk and L. Visarn, Nonequilibrium numerical modeling for combustion of LPG within porous media, International Journal of Heat and Mass Transfer., 143, (2019): 118551.
6. T. Madhiyanon, P. Sathitruangsak and S. Soponronnarit, Effect of swirl secondary air injection on rice husk combustion in a shortcombustion-chamber fluidized bed combustor using nozzle-type air distributor, Journal of Research and Applications in Mechanical., 1,(2011): 77-82.

7. K. Wasinarom, J. Charoensuk, Experiment and Numerical Modeling of Stratified Downdraft Gasification Using Rice Husk and Wood Pallet, BioResources, 14, 3(2019): 5235 - 5253.

8. C.D. Blasi, Dynamic behavior of stratified downdraft gasifiers, Chemical Engineering Science., 55, (2000): 2931-2944.

9. S. Dasappa and P.J. Paul, Gasification of Char particles in packed beds: analysis and results, International Journal of Energy Research., 25, (2001): 1053-1072.

10. J. Amir, J. Gunnar I. Hellstrom and T. Staffan Lundstrom, Numerical Derivation of Dispersion Coefficients for Flow through Three-Dimensional Randomly Packed Beds of Monodisperse Spheres, AIChE Journal., 60, 2(2014): 749-761. 